\title{
Title: Work and care opportunities under different parental leave systems: gender and class inequalities in northern Europe
}

\begin{abstract}
This article analyses public parental leave in eight northern European countries, and assesses its opportunity potential to facilitate equal parental involvement and employment, focusing on gender and income opportunity gaps. It draws on Sen's capability approach and Weber's ideal-types to comparative policy analysis. It offers the ideal parental leave architecture, one which minimizes the policy-generated gender and class inequality in parents' opportunities to share parenting and keep their jobs, thus providing real opportunities for different groups of individuals to achieve valued functionings as parents. Five policy indicators are created using benchmarking and graphical analysis. Two sources of opportunity inequality are considered: the leave system as the opportunity and constraint structure and the socio-economic contexts as the conversion factors. The article produces a comprehensive overview of national leave policies, visually presenting leave policy across countries. Considering policy capability ramifications beyond gender challenges a family policy-cluster idea and the Nordic-Baltic divide. It demonstrates that leave systems in northern Europe are far from homogenous; they diverge in the degree to which they create real opportunities for parents and children as well as in key policy dimensions through which these opportunities are created.
\end{abstract}

Key words: family policy, gender and class, capability, comparative analysis, policy indicators, Nordic and Baltic 


\section{Introduction}

Comparative welfare state research continues to describe the Baltic states according to their specific historical and geopolitical context, largely lumping them into a geopolitically convenient, homogenous 'Eastern European' cluster. Two comprehensive studies of family policy in 'Eastern Europe' (Szelewa \& Polakowski 2008; Javornik 2014) reveal significant intra-group variation, with the Baltic states not only representing different policy models, but following different trajectories after the collapse of the Soviet Union. However, despite their geographical proximity and shared reputation for high female employment, their family policies have not been systematically compared with those in an established cluster of the Nordic welfare state regime. Few earlier studies that include this group report contradictory findings, either separating the Nordics from the Baltics (Ciccia and Bleijenbergh 2014) or grouping Estonia into the Nordic cluster but not Latvia (Lohman and Zagel 2015). Interestingly, however, the Nordic states but also Lithuania and Estonia are considered to have the best parental leave policies in the world (Weller 2016). This challenges single policy cluster idea and invites further research into policy design, particularly because the Baltic group received comparatively little attention during the initial years of considerable focus on the post-socialist transition, and little remains known about their recent policy developments.

Family policies, of which parental leave is the most salient feature, are in a state of flux across Europe. In some countries austerity measures have stalled progress in legislation and practice, others have extended their rights, especially to fathers. Different ways in which state interventions have been made provide a constellation of significant interest for gender equality developments (Saxonberg 2013). With family policies being central to the current transformations of the welfare states, policy programming on parental leave (used hereafter as an umbrella term for all types of employment-based child-related leave rights) ${ }^{1}$ is emblematic of interventions that cut across domains such as employment, family, children and childcare, gender and living standards. 
Against this background we analyse parental leave in eight northern European countries, to examine how it shapes individual's real opportunities to 'be and do' around the family's first critical turning point - the arrival of a child.

Earlier comparative studies of leave policies do not comprehensively accommodate how different elements of the socio-economic contexts impact the way legal entitlements shape parents' real opportunities to use leave. Only few scholars highlight how parental orthodoxies, working cultures and economic constraints are key barriers to parents sharing parenting (e.g. Hobson et al. 2011; Saxonberg 2013; Gröndlund and Javornik 2014; Kurowska 2016). However, they do not investigate these differences within countries. The general focus on inequalities in opportunities has rendered largely invisible from the work-family debates the types of opportunity imbalances that are likely to impact parents differently, e.g. financial costs being the key concern for lowincome parents viz-a-viz opportunity costs for top income earners (but Hobson et al. 2011, 2013; Warren 2015). Previous studies of this interlink largely focus on instruments other than parental leave, assuming equal effects across socio-economic groups. Such considerations have capability ramifications; if comparative work-family policy analysis is to better represent class inequalities, this should be more fully conceptualized. This opens up both the conceptual and analytical space for our comparative analysis to consider the often neglected issue of gendered access to policy instruments across income groups. Parental leave represents a particularly fruitful area for methodological and conceptual reflections in comparative family policy analysis, an issue we seek to address.

We focus on leave as a specific instrument of work-family policy, whose design, embedded in socio-cultural and economic contexts, expresses multiple interpretations of gendered and class parenting opportunities. Methodological innovation we propose is that of conceptualising parental leave as a real opportunity structure for parents to achieve valued functionings (beings and doings 
after a child is born), focusing on gender (as proposed by Ciccia and Verloo 2012; Saxonberg 2013; Kurowska 2016) and income inequalities (as proposed by Warren 2015).

To analyse the role of public policy in shaping gender and class (in)equality in real opportunities to achieve a work-family fit, we[G1] merge Javornik's (2014) comparative methodology based on Weber's ideal-type approach with Kurowska's (2016) adoption of Sen's $(1985 ; 1999)$ capability approach to family policy research. This combination allows us to develop ideal-type leave architecture that reduces policy-related sources of gendered and classed inequalities in opportunities. We conceptualise [G2]real opportunities as three interconnected 'valued functionings' (Sen 1999) we deem valuable for mothers, fathers and the child - i.e. the opportunity to stay in the labour market while having a child; to care personally for a child; and to be cared for by both parents. We offer a conceptual model to examine how leave affects interpersonal variations' (Sen 1989; 1993) of the mother and the father (the agency), creating and constraining possibility to make a genuine choice to use and share leave[G3] to achieve these valued functionings. Using this framework we compare leave systems in the Nordic and Baltic country groups. [G4]

Our analysis demonstrates that national leave entitlements present material opportunities (resources) that shape the boundaries of what is possible for parents and the child and pave the way towards policy uptake. However, multiple pressures and hurdles inevitably embedded in socioeconomic contexts affect parents' real opportunity to claim statutory entitlements, and thus to make genuine choices about their parenting practices around childbirth. The article continues with a theoretical discussion to set the conceptual framework of the analysis. The next section presents national policy designs to identify and understand connections between policy and capabilities across social groups. It concludes by critically reflecting and offering new directions for future comparative policy analysis. [G5] 


\section{Theorising [G6]parental leave as real opportunity structure across gender and income}

\section{lines-[G7]}

The birth of a child represents a turning point in any family's life. This change most significantly affects women because the childbearing years correspond with the years of their core economic activity (when wages and skills should continue to grow). Moreover, care has long been a "woman-specific concept" (Daly and Lewis 2000, p. 283) and motherhood remains one of the main determinants of women's lower activity in the labour force, restricting their access to adequate income over the life course and into retirement. For men, however, the employment rates and the number of hours in work generally increase but their access to time off from work to take care of a child is more limited.

Comparative welfare state research highlights that the welfare states differ in the extent to which they consider parents' uneven capability to invest in paid employment and the family (e.g. Korpi 2000; Leitner 2003; Saraceno and Keck 2011). According to Wilson (1977, p. 9), the welfare state is "not just a set of services; it is also a set of ideas about society, about the family, and - not least importantly, about women who have a centrally important role within the family, as its linchpin". Every state chooses its own combination of policy instruments, i.e. the services, the money to purchase services and/or familial care (Korpi 2000). [G8]These choices represent the framework within which companies and individuals operate, making it easier/harder to be a 'working mother' and 'active father' in some countries than others. As Orloff (1993, p. 303-4) explains it, "... the character of public social provision affects women's material situations, shapes gender relationships, structures political conflict and participation, and contributes to the formation and mobilisation of specific identities and [G9]interests."[G10]

The post-2008 welfare states increasingly assume that men and women equally need to earn for their own social security. However, they neither assume equal obligations to care nor the child's 
opportunity to be cared for by both parents. Of the various work-family policy provisions available cross-nationally parental leave facilitates parental care for the youngest while allowing parents to keep their job. Its design however differently enables or constrains parents' real opportunities, either by exacerbating or reducing gender and income inequalities (e.g. Gornick and Meyers 2003; Ferrarini 2006; Misra et al. 2010; Javornik 2014). We argue that policy design critically frames the conditions under which women can access and engage with employment opportunities over their lives as well as men's access to parenting over the family's lifecycle (also Leitner 2003; Mandel and Semyonov 2005). That is, public policy on parental leave sets 'the rules of the game' (North 1990), by endorsing, legitimizing and re-producing 'ethos' of social norms and parenthood practices (Hobson et al. 2011: 173). It creates opportunities and constraints for parents to make claims at various institutional settings, thus affecting their capabilities to achieve work-family fit (Hobson et al. 2011). This provides a theoretical perspective on how the welfare state as a legislator and benefitand service supplier can use parental leave to challenge or reinforce gender roles, thereby framing parents' and child's capabilities.

Maternity and paternity leave (or the quotas) are by default gender-specific but the key distinction in opportunity is that fathers are often not offered the same period of leave as women nor is paternity leave stipulated by international conventions. Moreover, leave is delivered at the company level, where power and negotiations among employees and employers shape the practice (Bardach 1977; Haas and Rostgaard 2011). Limited resources, but also competing interpretations, organisational culture and unconscious gender bias (Benschop and Verloo 2011) all affect parents' access to policy opportunities (Skinner 2005). That is, the o[611]rganizational practice may make parents reluctant to claim the entitlements (e.g. Starrels 2009), particularly when this could result in discriminatory treatment. Furthermore, parental orthodoxies ${ }^{2}$, i.e. normative expectations of what proper parenting entails, could make parents, particularly fathers, reluctant to participate in policy programmes, thereby limiting child's opportunity to be with both parents. Against this 
background we argue that individual and non-transferable entitlements are key to real opportunities for mothers and especially fathers, providing normative guidelines for 'proper' fatherhood, sense of entitlement and opportunities for making claims in the workplace.

Miller and Ridge (2013), focusing on single mothers in the UK, argue that accessing statutory entitlements is more challenging for low-income [G12]parents. Their financial hardship and fears over income loss are crucial for understanding working-class everyday lives (Warren 2015). Thus, income support benefit is the leave's salient feature particularly because of the deepening economic inequalities.

The replacement levels are not only crucial for class, but also for gender. The neoclassical economic theory and the human capital thesis help us to conceptualise this dynamic. The former [G13]argues that labour supply is a (rational) consumption choice between one's market income and time spent outside paid work (e.g. Becker 1965, 1981). Using the 'time allocation model' Becker explains that women supply labour as long as their additional earning purchases more goods and services than required to make up for the lost home production and leisure. ${ }^{3}$ Thus, when leave is poorly compensated, the magnitude of the household income shock is higher. This is particularly relevant in countries at lower levels of economic development, with more pronounced financial concerns (Grönlund and Javornik 2014). Plantenga and Remery (2005: 48) however demonstrate that the income shock is lower when the leave is used by women because of the gender pay gap. This means that, in practice, "insufficient parental benefit is a structural incentive for female childcare at home" (Leitner 2003: 372). [G14]

However, the human capital thesis, using the 'opportunity-cost effect' (e.g. Del Boca et al. 2008), argues that rational economic actors use human capital stock as profitably as possible. As one's education increases, the opportunity costs of staying out of paid employment grow and equal 
the prevailing wage for individuals with the same educational level, experiences and skills (Mammen and Paxson 2000: 142-145). Considering the educational homogamy among couples, parents with higher income have more opportunities to take leave, relative to those constrained by household income need (e.g. Steiber and Haas 2009: 646). That notwithstanding, their opportunity costs from staying out of the job market are higher, regardless of the benefit rate (Görlich and de Grip 2009). With reference to this thesis, [G15]a rise in benefits levels shifts the cost-benefit relationship (Kangas and Rostgaard 2007: 248) for both women and men across income groups (Fagan and Hebson 2005: 8). But leave may exacerbate gender and class inequalities when the benefit cap is imposed: a limit on the total amount of benefit that people can get reduces the effective replacement rate, in particular among higher income groups, causing a household income shock. In fact, most European countries have benefits capped, with Denmark being a prominent case: their leave benefit cap level equals to approx. 50 per cent of the average wage, meaning that the majority of eligible parents are provided with less than 100 per cent of the formal replacement rate (Koslowski et al. 2016). ${ }^{4}$ Benefit caps inevitably reduce effective replacement rates, thus creating an opportunity gap between mothers and fathers across income groups.

The opportunity gaps embedded in public policy frame individual actions, but have not been systematically conceptualized in comparative family policy analysis. As Hobson et al. (2011) highlight, there is a need for an agency-centred analytical framework that allows us to understand how the use of policy is formed by structural opportunities and constraints, but also opportunities embedded into the policy that privilege some and marginalize others. To contribute new perspectives to comparative family policy research, we offer a new method of evidencing the realisation of entitlements for parents across countries as discussed below.

\section{Analytical framework for comparative analysis of parental leave}


All European countries have parental leave policies in place, yet we know little about the mechanisms underlying their use. Gendered and classed opportunities embedded in public policy are of particular interest to this article, as we conceptualize the links between policy design and inequalities in parents' real opportunity. To explore these in a country-comparative perspective, we merge the capability approach (hereafter referred to as CA) with Weber's ideal types analysis; this innovative application allows us to make explicit the national policy design by revealing the underlying gendered and classed opportunities and constraints embedded in national policy on parental leave.

$\mathrm{CA}$ as a theoretical perspective was originally proposed for conceptualising and measuring well-being and human development (Sen 1985; 1999). It is pertinent to our analysis because it facilitates theoretical conceptualization of parental leave in terms of real opportunity for people to achieve valued functionings such as the opportunity to stay in the labour market while having a child; to care personally for a child; and a child's opportunity to be cared for by both parents (figure 1). Furthermore, it allows us to define the (dis)advantageous effects of leave policy across socioeconomic and cultural contexts. Two CA notions are key to our analysis: (1) 'functionings' and (2) 'capabilities'. In this concept, functioning is any being or doing, whereby we focus on 'valued functioning' as beings and doings intrinsically valuable to people (Sen 1999). Capabilities, then, are the valued functionings that one is able to achieve. We consider caring for a child while working a valued functioning, and the real opportunity to stay at home to care for a child and to keep a job as the corresponding capability.

Drawing on CA we argue that people may have access to the same formal policy means (i.e. statutory entitlements). But whether they have the same real opportunity to use those to achieve valued functioning depends on the 'conversion factors' (figure 1). For example, fathers could have similar legal rights (formal opportunities) to parental leave and pay as mothers but their 
real opportunities to use leave may be affected inter alia by economic constraints and/or parental orthodoxies that cast mothers as proper carers. That is, the same legal right may be converted into different real opportunities because of the socio-economic and cultural contexts (conversion factors). This is pertinent to evidence-based policy-making where any omission of socio-economic and cultural contexts could be misleading (Saxonberg and Szelewa 2007; Kurowska 2016).

Another key distinction is that of 'observed functionings' (Robeyns 2005). These are what we observe people do or are. In standard family policy analysis, this[G16] would translate into a variable such as leave uptake; this captures the use of policy, which may be a result of either the real opportunities that parents have or their own choice. CA allows us to distinguish between these two. For example, we could explain fathers' lower leave uptake by their individual choice not to use it; or the opportunity and constraint structures framing their choice. Although fathers' entitlement to parental leave may be equal to mothers', fathers may not have a real opportunity to exercise it because of the social norms casting mothers as 'proper' carers and/or normative expectations of how a proper male-employee behaves (e.g. Pfau-Effinger 2012). To assess whether the policy provide[G17]s parents with real opportunities to care and work, both sources of inequalities (i.e. those stemming from a difference in statutory entitlements and those from the 'conversion factors') should be considered.

In previous studies, single/composite indicator[G18]s have often been used as an uncontested variable to measure family policy across countries (Lyness et al. 2012). These have been subject to much academic controversy (e.g. Fagan [619]and Hebson 2005; Gilbert 2008; Javornik 2014). We subscribe to this critique because such indicators are less adequate predictors of multifaced capabilities (real opportunities). [G20] 
Against this background, [G21]we need to first determine the features of parental leave that are associated with an advantageous real opportunity effect across genders and class lines. In the absence of clear criteria for distinguishing more/less valuable functionings of parental leave, we draw on Hobson's application of CA to work-life research, which identifies work-family balance as a valued functioning (2014: 6-7). However, her conceptualization is not adequate[G22] for our purpose because it draws on outcome indicators (of observed functionings) to reflect the capabilities, and conflates means with conversion factors. ${ }^{5}$ Thus, we refine the valued functionings as three interconnected opportunities: to stay in the labour market while having a child; to care personally for a child; and to be cared for by both parents. We conceptualize leave as a 'policydriven means', which, embedded in the socio-economic and cultural context[G23], represents a real opportunity structure for people to achieve valued beings and doings. This allows us to distinguish between gender and class inequalities in real opportunities that can result from either the salient features of parental leave (means) or the 'conversion factors' - i.e. parental orthodoxies, work cultures and economic constraints that may impact the translation of means (figure 1). Another key distinction is in our analysis is that these are related to three parties involved: the mother, the father and the child, who has been often overlooked in comparative family policy research (Kurowska 2016). [G24]

[Figure 1. Theoretical framework]

\section{Ideal parental leave}

There is no simple formula to determine the ideal parental leave architecture, more so as the efforts made by governments to support families are multi-dimensional (Misra et al. 2010). Considering parental leave as the opportunity structure for parents an ideal public policy would treat everyone equally, providing a real[G25] opportunity for equal parental involvement in the raising 
of children across gender and income lines. ${ }^{6}$ Thereby, the conception of equality is shaped by a commitment to the social value of parenthood (Javornik and Oliver 2015).

Against this background we assess whether, and how national leave systems create inequalities in real opportunities to achieve valued functionings, considering gender and class (operationalised as income inequality) in diverse socio-economic and cultural contexts. Focusing on traditional policy indicators would conceal any trade-offs in real opportunity. To take up this challenge, we draw on the method offered by Javornik (2014) using a set of organising principles that guide comparative leave analysis. Her ideal-types approach assesses and compares parental leave policy against a set of standards across countries, focusing on women's opportunities to stay in the labour market and fathers' to care for the child. It thus fits particularly well wit[G26]h [G27]our study. However, our analytical focus and aim diverge, and hence we develop different criteria to assess policies in our sample countries as explained further below. [G28][G29]

\section{Policy components and assessment criteria}

Following Javornik's (2014) indicator development, [G30]we construct five indicators as salient features of leave; these distinguish between socio-economic contexts and assess efforts made by governments to support equal parental involvement in childcare across gender and income lines (table 1). Data on leave is sourced from the 2016 International Network on Leave Policies and Research country and comparative reports (Koslowski et al. 2016). This is the most comprehensive source of information about parental leave to date. Information is collected annually by national expert teams. Both structure and terminology are standardised, to ensure comparability. Because Latvia was not included in the report, data was obtained from its State Social Insurance Agency. Data for the indicators was obtained from the OECD.Stat and OECD Family Database (2016), and Eurostat Database (2016), to ensure commensurability. Data refers to 2015 unless otherwise specified. The indicators are explained in the remainder of this section and summarised in table 1. 
The equality of treatment (Indicator 1) assesses whether or not policy enables equal access to paid time off for both parents. We argue that maintaining enhanced entitlements for mothers without mandating equivalent benefits for fathers creates a disincentive for a couple to share leave. We measure this as the ratio of the full-rate equivalent (FRE) ${ }^{7}$ of a non-transferable leave for fathers to the FRE of an individual and non-transferable leave for mothers. Following the EU law, w[G31]e acknowledge the uniqueness of pregnancy (i.e. mothers need to leave for medical reasons). This allows for a derogation from the principle of equal treatment, allowing women to be treated more favourably than men in connection to pregnancy or childbirth (Javornik and Oliver 2015). Thus, we apply the difference approach and accommodate the gap between policy ambition and the perpetuation of gender bias in legal framework (see table 1 for details).

Fathers' access to financially viable ${ }^{8}$ non-transferable leave (Indicator 2 ) assesses the absolute length of a financially viable, non-transferable leave for fathers. This reflects financial viability of both length and the payment. This is relevant because fathers are more sensitive to any income loss (Bruning and Plantenga, 1999: 196; Fagan and Hebson, 2005: 95). The replacement rate determines whether fathers take leave at all. Ideally, policy recognizes the social value of fatherhood and replaces previous earnings at 100 per cent. This is rarely the case and hence causes a household income shock. We assume that the shock depends on the national living standards, i.e. a lower replacement rate is financially more viable in more affluent societies. To accommodate this, we first assess the financial viability of leave. We calculate the Adjusted Replacement Rate (ARR) - that is, we adjust the national crude income replacement rate by multiplying it by a country's GDP index (per capita in PPS; EU28=100 per cent; Eurostat 2016). To illustrate, the income replacement rate of a non-transferable parental leave for fathers in Sweden was 77.6 per cent in 2015, and 80 per cent in Latvia. Their GDP indices were 123 and 64 per cent, respectively. Thus, their ARRs were 95.5 per cent for Sweden and 51.2 per cent for Latvia. [G32] 
Then we calculate the length of a financially viable leave. We only include countries whose ARR was at least 70 per cent (a threshold for a financially viable benefit) ${ }^{9}$. Other countries are assigned the lowest score of 1 (table 1). We then assess this against the optimal length of the nontransferable leave. Here we follow the [G33]EU guideline prescribing a minimum of 14-week nontransferable maternity leave (Directive 92/85/EEC); applying the gender-equality principle we consider the ideal for fathers to be at least three months. Therefore, the longer the financially viable non-transferable leave for fathers, the higher the score (table 1).

\section{By contrast, Indicator 3 assesses the financial viability of a transferable (family/joint)}

leave. Namely, a country may provide leave as a family entitlement, and allows both leave and pay to be transferred between parents. We argue that the income-replacement rate determines who takes leave and for how long. The rate, therefore, [G34][G35]reflects whether or not the family leave provides incentives for parents to share leave (i.e. for fathers to use it). By contrast to Indicator 2, however, sharing this joint leave is sensitive to gender pay gaps. We assume that the household income shock is lower when leave is used by a woman because of the lower average income (Eurostat 2016). Thus, to create real opportunities for shared parenting, the ideal income replacement rate of the transferable/family benefit should be 100 per cent. This too is rarely the case. Therefore, we adjust the ARR for the gender pay gap, and create a Gender-sensitive Adjusted Replacement Rate (i.e. GARR): we multiply ARR by the ratio of women's average earnings to men's average earnings in each country ${ }^{10}$ (using latest available data for 2014; Eurostat 2016). To illustrate, the ARR for Sweden was 95.5 per cent and 51.2 per cent for Latvia. Their earnings ratios were 85.4 and 84.8 per cent, respectively. Thus, their GARRs equal 81.5 and 43.42 per cent, respectively, meaning that the Swedish scenario is closer to the ideal than the Latvian (table 1). 
Equality in effective income replacement rate (Indicator 4) assesses the effective income-replacement rate, i.e. the effect of a benefit cap on the financial viability of leave. Most systems operate with a benefit ceiling; this means that the effective replacement rate of income coverage by public benefit is lower, in particular for parents whose income exceeds the set amount. This disrupts gender equality across income groups (i.e. gender pay gaps). Ideally, leave benefit would have no ceiling; alternatively, the cap is set so high that the majority of employees would not be affected (i.e. at two times the average wage). To estimate effective income-replacement rate, we calculate the ratio of the benefit cap to the average wage in the country: the lower the ratio the higher the inequality (data refers to 2015, using the OECD 2016).

Finally, the congruency of leave and public childcare (Indicator 5) assesses whether or not the policy provides real opportunities for mothers to resume employment after the end of paid leave. We apply Javornik's (2014) criteria to measure the gap between paid leave and childcare services. In an ideal scenario, public childcare becomes available before the earnings-related leave ends. Scenario close to this is when earnings-related leave and services are contiguous. By providing a place in day care without delay, the state also sends a message about proper parenthood (i.e. acceptability of public childcare and thus mothers' employment; Gornick and Meyers, 2003: 197206). Alternatively, any gap disrupts real opportunities for parents, particularly for mothers' to resume employment.

\section{Benchmarking with scoring}

Because not all policy components are quantifiable indicators, we translate them into measurable variables applying Javornik's (2014) scoring method. This assesses the conformity of each component to an ideal policy (real opportunity). Specific 'standards' are used, assigning a score using an 8-point scale, based on the component's real opportunity potential: the higher the score, 
the higher the potential. Each component is scored repeatedly across countries using a scale with a four-value set of 1-2-4-8 (table 1):

- 8 indicates that the component is close to the ideal (real opportunity)

- 4 that it is moderately close

- 2 that it is far from ideal, and

- 1 that the component is the furthest from the ideal.

8 is a maximum because 10 or 100 (ordinarily used in other studies) have too strong an influence on the results, and 1 is used as a minimum because of the multiplicative method used for calculating the composite index. ${ }^{11}$ In our study, [G36]the individual scores are the main results but the method allows for a composite index to be calculated (see Javornik 2014, p. 249).

[Table 1. Policy dimensions, assessment criteria, scores]

\section{Graphical analysis}

In this final step, [G37]we analyse leave systems against an ideal provision, using Javornik's (2014) graphical representations of radar charts. The advantage of this method is that policies can be easily read from the chart, reflecting the opportunity potential. Each chart represents one country and comprises of five equiangular spokes, one for each indicator. Their length is proportional to the score, and ranges between 1 and 8: the higher the score the higher the opportunity potential. The line connecting the indicators into a radial figure gives the policy[G38] a spider web appearance: the larger the area the closer to the ideal. The spider web illustrates the policy's opportunity potential for parents to keep their job while having a child, to care for the child themselves, and the child's to be cared for by both parents. Opportunity potential of each component can be read from the chart, clockwise: the top spoke illustrates equality of access to paid time off, followed by the 
opportunity for fathers to use leave, gender equality of leave (i.e. child's opportunity to be with both parents), equality of opportunity across income groups, and mothers' opportunity to resume employment immediately after leave. The larger the spider web the closer the policy to offering real opportunities.

\section{Results}

Figure 2 demonstrates how diversified national policies on leave were in 2015, with Sweden being the closest to and Latvia the farthest from the ideal provision of real opportunity for both parents and the child. We can see that countries provide different opportunity structures, failing to fully support equal parental involvement across gender or/and income lines.

[Figure 2. Parental leave policies, 2015 (scores on a scale 1-8, maximum $=8$ ), by country]

In our study, only Sweden and Iceland provide comprehensive support for shared parenting, and thus a real opportunity for the child to be cared for by both parents. This is indicative of the social value ascribed to fatherhood and represents a real opportunity for fathers to take a more active role in childcare. This is achieved by equal treatment of parents in terms of leave length and financial compensation. Both countries offer post-natal leave as a single period and do not distinguish between different types of leave. That notwithstanding, they allocate a portion to the mother and a portion to the father as an individual and non-transferable right (to 3 months each), and the rest is available as a family's joint right. The Norwegian model comes close but with a shorter non-transferable paid leave for fathers (ten weeks). The transferable period is financially viable in all three countries, providing a real opportunity for parents to share it. However, neither of the Nordic states provide real opportunities for parents across income groups because of the relatively low benefit caps. Furthermore, in Finland and Denmark the legal opportunity for fathers to use leave is not likely to be converted into a real opportunity (i.e. child's real opportunities to be 
with both parents) because fathers and mothers are not treated equally (with relatively short father quotas, of nine and two weeks, respectively) and/or financially unviable sharable leave. [G39]

The Baltic States do not provide real opportunities for parents to share leave either. Lithuania, [G40]however, [G41]is an exception. While Estonia and Latvia provide two weeks of paternity leave, fathers in Lithuania are entitled to twice the paid leave time. Furthermore, parents are treated more equally in Lithuania: the ratio of the full-rate equivalent (FRE) is five times higher in Lithuania (53.7 per cent) than in Estonia (9.1 per cent) and Latvia (11.7 per cent). Moreover, parents in Lithuania can share a year-long financially more viable leave; this provides opportunities for a child to spend more time with both parents. However, there is no entitlement to public childcare after the end of this one-year leave. Therefore, parents may resort to a two-year parental leave, of which the first year is paid at 70 per cent and the second at 40 per cent. However, lower living standards and wider gender pay gaps make this financially less viable, constraining both child's opportunities to be with both parents and mothers' to remain in employment.

Surprisingly, parental leave systems in the Baltics provide the [G42]equal opportunities across income groups than in the Nordics because of their higher effective income-replacement rates. For example, Latvia does not impose benefit caps at all, thereby not reducing the replacement rate of income coverage. Similarly, the Lithuanian and Estonian systems operate with benefit ceilings that are less likely to damage the majority of parents (e.g. in Lithuania the benefit cup equals to 3.2 times the average wage). [G43]

By contrast, Denmark has the benefit cap for publicly financed parental leave set to only a half of the national average wage. Its public policy, [G44]therefore, [G45]does not provide financially viable payment benefit for the majority of workers. This is largely compensated by the provisions via collective agreements; however, these may not be equally generous across populations. Namely, 
75 per cent of the Danish workforce was covered by collective agreements in 2011; the incomereplacement benefit for these workers was enhanced up to the previous earning by the employer (Bloksgaard and Rostgaard 2016). However, this share is declining, particularly among younger workforce; this means that fewer workers get access to enhanced benefits via collective agreements (ibid.). Collective agreements play a similarly significant role in Sweden, Norway and Finland, providing enhanced income replacement during a leave[G46]. On the one hand, this [G47]is an opportunity to advance progressive changes in policy provision, of which Denmark is a good example: in 2007, the industrial sector introduced paid father's quotas into parental leave and a similar instrument was introduced for the public sector employees in 2008 (ibid.). On the other hand, such system creates inequality within the country.

Countries in our study further diverge in how they support women's continuous employment. While Denmark, Finland, Sweden and Estonia facilitate mothers to resume employment immediately after leave (by guaranteeing a place in public childcare without delay), other four lag behind. Whilst there is no gap between the end of paid leave and public childcare in Sweden and Norway, in Norway, [G48]a child must be born before 1 September to be guaranteed a place in the new school year - this clearly creates a gap in practice (Brandth \& Kvande 2016: 5). Furthermore, Iceland provides no legal entitlement to public childcare for the under-2s, and the gap is the widest in Lithuania and Latvia. Policy combination with no entitlement to public childcare diminishes leave's real opportunity potential because it locks mothers into home care (constraining shared parenting) and disrupts income equality (commercial childcare is often an unaffordable alternative). Overall, the results demonstrate that parental leave policies do not fit neatly the Nordic-Baltic divide. Moreover, there are many relevant differences within each country cluster, i.e. between the Nordic and between the Baltic states.

\section{Discussion and conclusion}


A growing body of comparative welfare state literature focuses on work-family policies. However, they often overlook whether, and how policy translates into real opportunity structures available to parents under different socio-economic contexts. This article seeks to contribute to this research stream by examining the most prevalent form of work-family policy - parental leave, the instrument that lies at the intercept of employment, family and children, childcare and gender, and living standards. Theoretical innovation it offers is in conceptualising leave as a real opportunity structure for parents to achieve valued functionings; that is, child's real opportunity to be cared for by both parents and parent's opportunities to stay in the labour market while having a child.

Our analytical framework is based on Kurowska's (2016) capability approach to family policy analysis, merged with Javornik's (2014) ideal-types comparative policy analysis. This combination enables us to define the ideal parental leave design and to examine parental leave systems of eight northern European countries. It acknowledges the impact of gender roles (culture) and socio-economic constraints (i.e. sensitivity to household income shocks and gender pay gap) as the conditioning 'conversion factors' that translate institutional (formal) opportunities into the real ones (Ciccia and Verloo 2012; Saxonberg 2013; Warren 2015; Kurowska 2016). An ideal-type leave is defined to minimize the policy-generated gender and class inequalities in parents' real opportunities to use leave, acknowledging that these are not embedded only in the leave system but stem also from the 'conversion factors' - i.e. variability in socio-economic contexts.

The benefit of applying benchmarking and graphical analyses to comparative policy study is threefold. First, it allows us to go over policies with a fine-tooth comb, using statutory entitlements as key information about the national leave system. This is commensurable across countries and aptly depicts the leave's salient features. Second, it develops a nuanced and comprehensive overview of national policies on leave. This helps to identify patterns that remained undetected in earlier research, and thus the variation among countries that are often treated as 
representatives of a single policy model. And third, the resulting indicators enable a simple visual representation of policies across countries; although the results are relationally linked to the countries included in the study, the approach itself is applicable to a larger set of countries.

The results challenge existing knowledge about selected countries. First, leave policies in the Nordic group are far from homogenous. This is demonstrated in the degree to which leave creates real opportunities across gender and income (with the Swedish system being the most comprehensive and the Danish the least) as well as in the dimensions through which these opportunities are shaped. For example, the results for Sweden confirm its overall gender-equal character: its system provides fathers with real opportunity to use leave (and thus a child with real opportunity to be cared for by both parents) and mothers to stay in the labour market. However, equality of opportunity across income groups is less pronounced. Other four countries provide less opportunity in one of the two dimensions: while Denmark and Finland facilitate mothers' opportunities to stay in the labour market, they are less supportive of active fatherhood. By contrast, Iceland and Norway create child's opportunity to be with both parents but hinder mothers' swift return to work by preserving commercial service markets for the under-2s.

Second, countries in the Baltic group diverge in significant ways. Estonia mirrors the Danish leave system (but with longer paid leave), providing more opportunity for a dual-earner than a dual-carer family model. This supports Lohman and Zagel's (2015) locating Estonia in the Nordic cluster. Lithuania, [G49]however, [G50]exemplifies how a national policy may constrain parents' real opportunities in different ways. Its leave is closer to an ideal architecture than those of Estonia and Latvia (this supports Javornik 2014). By considering only the equality of parental involvement it could be paired with Fraser's (1994) universal caregiver model. However, the state does not secure access to public childcare after a shorter fully-paid parental leave. Instead, it offers a financially less viable extended leave (particularly for fathers). This is shaped by the subsidiarity principle, which stresses the primacy of financially supported family childcare. Thereby, it 
constrains mother's opportunity to return to the labour market. Such inconsistency, often overlooked in previous studies, can only be revealed when using more nuanced policy indicators.

In conclusion, our study challenges a single policy cluster idea and offers a comprehensive policy overview. It supports earlier findings that family policies do not fit neatly the established welfare state typologies (e.g. Leitner 2003; Ciccia and Verloo 2012; Korpi et al. 2013; Thévenon 2013; Javornik 2014; Dearing 2016). This reiterates calls for deconstructing the welfare state into policy domains (e.g. Kasza 2002; Leitner 2003; Saraceno and Keck 2011) and for using more nuanced indicators in cross-national family policy analyses (Javornik 2014). The analytical framework enables developing new hypotheses and provides a valuable analytical instrument for academic and non-academic use, which could be employed to other policy domains and countries.

That notwithstanding, leave policy is not typically designed for diverse populations, but rather for a dual-earner heterosexual couple. To fully operationalize the proposed model of opportunity structure (real opportunities and valued functionings), future research should seek ways to more comprehensively incorporate meso- and company-level provisions and equality of opportunity for diverse [G51]groups of parents (e.g. same-sex, adoptive and single parents, parents with more children and disabled children, resident and non-resident parents). Our empirical part is also limited in its ability to accommodate a wider range of relevant conversion factors (e.g. individual-, household- and meso-level factors, cultural and socio-economic contexts such as beliefs, attitudes and norms, income needs and preferences, and social movements). Incorporating these would provide a complete landscape of the opportunity/constraint structure, strengthen the model's analytical and interpretative capacity, and improve modelling of policy implications and individual-level decision-making processes. This would better inform the public and company-level policy-making process that could even out the imbalances, and thus to provide real opportunities for individuals to achieve valued functionings once they become parents. [G52] 


\title{
Acknowledgements
}

The authors wish to thank (anonymized for blind review) and two anonymous referees for their critical reading of the drafts of this article. Responsibility for any errors rests with the authors.

\section{Funding}

This research received no specific grant from any funding agency in the public, commercial, or not-for-profit sectors.

\section{Notes}

\begin{abstract}
${ }^{1}$ Including individual and non-transferable rights for mothers (in the form of maternity and/or mothers' quotas in the system); father's individual and non-transferable rights (paternity and father's quota in parental leave); and joint rights for parents (transferable/sharable parts of leave), which allows us to compare different leave systems across countries.

${ }^{2}$ In terms of mothering, for example, media constructs personify polarized acceptable and unacceptable forms of motherhood. These constructs have recently set up the same polarized dynamics for men, but emphasising masculine economic reliability alongside emotional and caring involvement surpassing the traditional breadwinner role (e.g. the father who fails to look after his family versus the 'new man' who does). In many countries, this can be exemplified by the rise of the new rhetoric of 'shared parenting', which often constructs and results from parental and paternity leave [G53]system (Javornik and Oliver 2015).
\end{abstract}

${ }^{3}$ Reservation wage, i.e. the net wage at which an individual considers employment to be worthwhile, reflects the utility of time with the newborn child, including the value of home production, measured in the price of market production (Blau and Ferber 1992). [G54]

${ }^{4}$ The loss in effective parental leave replacement rate due to public provisions is made up for $75 \%$ of workers through collective agreements (Koslowski et al. 2016).

${ }^{5}$ Hobson (2014) does not make the distinction between means and converting factors and only identifies the latter. These include social rights, care benefits and services, organizational culture, social equality of jobs and working times/flexibility, in addition to individual factors (skills, gender, class, age, family support) and societal factors (cultural norms, social movements, media).

${ }^{6}$ It should be noted that policy provisions related to same-sex or adopting parents, whether or not regulated by national laws, are not subject of this study.

${ }^{7}$ We adapt the OECD (2016) methodology for calculating FRE and apply it to an individual and non-transferable leave available to each parent. Full details available at http://www.oecd.org/els/soc/PF2 1 Parental leave systems.pdf [G55]

${ }^{8}$ Previous studies largely use the term 'well-paid leave' to describe financially viable leave which does not discourage fathers from taking it (for them, financial considerations are particularly important). However, these studies use crude (legally defined) income replacement rates (RR) to define a well-paid leave. To avoid confusion we propose a new concept as described in the text.

${ }^{9}$ We use the median of the values proposed in the literature: Saxonberg (2013): 67\%; Wall et al. (2009: 36): 70\%; Gornick and Meyers (2003: 122): 80\%. 
${ }^{10}$ ARR is limited to 100 per cent. We assume that relatively high living standards do not render gender pay gaps or household income shocks irrelevant.

11 Javornik used the 1-8 scale to follow the principle of a geometric sequence so that logarithms used for her index score yielded an arithmetic sequence. We made several sensitivity tests for different scales (linear, different scores); the results have not changed[G56], and hence we consider her scale robust enough for our purposes. [G57]

\section{References}

Bardach, E. (1977). The implementation game: What happens after a bill becomes a law, Cambridge: MIT Press.

Becker, G. S. (1965). ‘A Theory of the Allocation of Time,' Economic Journal 75(299): 493-517.

Becker, G. S. (1981). A Treatise on the Family. Cambridge: Harvard University Press.

Benschop, Y. and M. Verloo (2011). 'Gender change, organizational change, and gender equality strategies', in: Jeanes, E., Knights, D. and Yancey Martin, P. (Eds.), Handbook of Gender, Work, and Organization, Chichester: Wiley, 277-90.

Blau, D. F. and A.M. Ferber (1992). The Economics of Women, Men and Work. New Jersey: Prentice-Hall.

Bloksgaard, L. and Rostgaard, T. (2016) 'Denmark country note', in: Koslowski A., Blum S. and Moss P. (eds.) International Review of Leave Policies and Research 2016. Available at:

http://www.leavenetwork.org/lp_and_r_reports/ (accessed 18 Nov).

Brandth, B. and Kvande, E. (2016) 'Norway country note' in: Koslowski A., Blum S. and Moss P. (eds.) International Review of Leave Policies and Research 2016. Available at:

http://www.leavenetwork.org/lp and $\mathrm{r}$ reports/ (accessed $1 \mathrm{Dec}$ ).

Ciccia, R. and I. Bleijenbergh. (2014). 'After the Male Breadwinner Model? Childcare Services and the Division of Labor in European Countries,' Social Politics 21(1): 50-79.

Ciccia, R. and M. Verloo (2012). 'Parental Leave Regulations and the Persistence of the Male Breadwinner Model: Using Fuzzy-Set Ideal Type Analysis to Assess Gender Equality in an Enlarged Europe,' Journal of European Social Policy 22(5): 507-28.

Daly, M. and J. Lewis (2000). 'The concept of social care and the analysis of contemporary welfare states', British Journal of Sociology 51(2): 281-98.

Dearing, H. (2016). 'Gender equality in the division of work: How to assess European leave policies regarding their compliance with an ideal leave model,' Journal of European Social Policy 26: 234-247.

Del Boca. D., S. Pasqua and C. Pronzato (2008). Market Work and Motherhood Decisions in Contexts. IZA Discussion Paper No. 3303, available at http:/ ftp.iza.org/dp3303.pdf (last accessed 15 Aug).

Duvander, A.-Z., Haas, L., and Hwang, P. (2016) 'Sweden country note', in: Koslowski A., Blum S. and Moss P. (eds.) International Review of Leave Policies and Research 2016. Available at: http://www.leavenetwork.org/lp and_r reports/

Esping-Andersen, G. (2009). The incomplete revolution. Adapting to women's new roles, Cambridge: Polity Press. 
Eurostat (2016). Gender pay gap statistics. Eurostat Statistics Explained. Available at at: http://ec.europa.eu/eurostat/statistics-explained/index.php/Gender_pay_gap_statistics (last accessed 4 November 2016).

Fagan, C. and G. Hebson (2005). 'Making Work Pay' Debates from a Gender Perspective: A Comparative Review of Some Recent Policy Reforms in Thirty European Countries. Brussels: European Commission.

Ferrarini, T. (2006). Families, States and Labour Markets: Institutions, Causes and Consequences of Family Policy in Post-War Welfare States. Cheltenham: Edward Elgar Publishing.

Fahlén, Susanne. 2014. 'Does Gender Matter? Policies, Norms and the Gender Gap in Work-to-Home and Home-to-Work Conflict across Europe,' Community, Work \& Family 17(4): 371-91.

Gilbert, N. (2008). A Mother's Work: How Feminism, the Market, and Policy Shape Family Life. New Haven, CT and London: Yale University Press.

Gornick, C. J. and K. M. Meyers (2003). Families that work. Policies for Reconciling Parenthood and Employment, New York: Russell Sage Foundation.

Görlich, D. and A. De Grip (2009). 'Human Capital Depreciation During Hometime,' Oxford Economic Papers 61:i98-i121.

Grönlund, A. and J. Javornik (2014). 'Great Expectations: Dual-Earner Policies and the Management of Work-Family Conflict - The Examples of Sweden and Slovenia', Families, Relationships and Societies 3(1): 5165.

Haas, L. and T. Rostgaard (2011). 'Fathers' rights to paid parental leave in the Nordic countries: Consequences for the gendered division of leave,' Community, Work and Family, 14(2): 175-95.

Hobson, B. (2014). 'Instroduction: capabilities and agency for worklife balance - a multidimensional framework,' in: B. Hobson (ed.), Worklife balance. The agency and capabilities gap. Oxford: Oxford University Press. 1-31.

Hobson, B. (2013). 'The Agency Gap in Work-Life Balance: Applying Sen's Capabilities Framework Within European Contexts,' Social Politics 18(2): 147-67.

Hobson, B., S. Fahlén and J. Takács. (2011). 'Agency and Capabilities to Achieve a Work-Life Balance: A Comparison of Sweden and Hungary,' Social Politics 18(2): 168-98.

Javornik, J. (2014). 'Measuring state de-familialism: Contesting post-socialist exceptionalism,' Journal of European Social Policy 24(3), 240-257.

Javornik, J. and E. Oliver (2015). 'Legal battles loom on shared parental leave from fathers not getting equal benefits' The Conversation: 14 December, accessed 8 January 2016 at https://goo.gl/BYunIE

Kasza, G.J. (2002). 'The Illusion of Welfare “Regimes”, Journal of Social Policy 31(2): 271-87.

Kangas, O. and T. Rostgaard, T. (2007). 'Preferences or institutions? Work family life opportunities in seven European countries,' Journal of European Social Policy 17(3): 240-56.

Koslowski A., Blum S. and Moss P. (eds.) (2016). International Review of Leave Policies and Research 2016. Available at: http://www.leavenetwork.org/lp and $\mathrm{r}$ reports/

Korpi, W. (2000). 'Faces of Inequality: Gender, Class, and Patterns of Inequalities in Different Types of Welfare States', Social Politics 7(2): 127-191. 
Korpi, W., Ferrarini, T. and S. Englund (2013). 'Women's Opportunities under Different Family Policy Constellations: Gender, Class, and Inequality Tradeoffs in Western Countries Re-Examined', Social Politics: International Studies in Gender, State \& Society 20: 1-40.

Kurowska, A. (2016). ' (De)familialization and (De)genderization - Competing or Complementary Perspectives in Comparative Policy Analysis? ', Social Policy \& Administration, early view, DOI: $10.1111 / \mathrm{spol} .12272$

Leitner, S. (2003). 'Varieties of Familialism. The caring function of the family in comparative perspective', European Societies 5(4), 353-75.

Lohmann, H., and H. Zagel. (2015). 'Family Policy in Comparative Perspective: The Concepts and Measurement of Familization and Defamilization,' Journal of European Social Policy 26: 48-65.

Lyness, K. S., Gornick, J. C., Stone, P. and Grotto, A. R. (2012). 'It's All About Worker Control over Schedule and Hours in Cross-National Context', American Sociological Review 77: 1023-1049.

Mammen, K. and Paxson, C. (2000). 'Women's work and economic development,' Journal of Economic Perspectives 14(4): 141-64.

Mandel, H. and M. Semyonov (2005). 'Family Policies, Wage Structures, and Gender Gaps: Sources of Earnings Inequality in 20 Countries', American Sociological Review 70(6), 949-67.

Millar, J. and T.M. Ridge (2013). 'Lone mothers and paid work: The 'family-work project,' International Review of Sociology 23(3): 564-77.

Misra, J., Budig, M. and I. Böckmann (2010). 'Work-Family Policies and the Effects of Children on Women's Employment and Earnings', Luxemburg Income Study Working Paper Series 543, Luxembourg: LIS.

North, D.C. (1990). Institutions, Institutional Change and Economic Performance. Cambridge: Cambridge University Press.

Orloff, A. S. (1993). 'Gender and the Social Rights of Citizenship: The Comparative Analysis of Gender Relations and Welfare States,' American Sociological Review 58(3): 303-28.

Plantenga, J. and C. Remery (Eds) (2005). Reconciliation of Work and Private Life: A Comparative Review of Thirty European Countries. Brussels: European Commission.

Pfau-Effinger, B. (2012). 'Women's Employment in the Institutional and Cultural Context,' International Journal of Sociology and Social Policy 32(9): 530-43.

Robeyns, I. (2005). 'The Capability Approach: A Theoretical Survey,' Journal of Human Development 6(1): 93117.

Saraceno, S. and W. Keck (2011). 'Towards an integrated approach for the analysis of gender equity in policies supporting paid work and care responsibilities,' Demographic Research 25(11), 371-406.

Saxonberg, S. (2013). 'From Defamilialization to Degenderization: Toward a New Welfare Typology,' Social Policy and Administration 47(1): 26-49.

Saxonberg, S. and D. Szelewa. (2007). 'The Continuing Legacy of the Communist Legacy? The Development of Family Policies in Poland and the Czech Republic,' Social Politics 14(3): 351-79.

Sen, A. (1985). Commodities and Capabilities. New Delhi: Oxford University Press. . (1989). Inequality Reexamined. Cambridge: Harvard University Press. 
—. (1993). 'Positional Objectivity,' Philosopby \& Public Affairs 22(2): 126-45.

(1999). Development as Freedom. Oxford: Oxford University Press.

Skinner, C. (2005). 'Co-ordination points: A hidden factor in reconciling work and family life,' Journal of Social Policy 34(1): 99-119.

Starrels, M.E. (1992). 'Attitude similarity between mothers and children regarding maternal employment,' Journal of Marriage and Family 54: 91-103.

Steiber, N. and B. Haas (2009). 'Ideals or Compromise? The Attitude-Behaviour Relationship in Mothers' Employment', Socio-Economic Review 7(4): 639-68.

Szelewa, D., and M. P. Polakowski. (2008). 'Who Cares? Changing Patterns of Childcare in Central and Eastern Europe,' Journal of European Social Policy 18(2): 115-31.

Thévenon, O. (2013). 'Family Policies in OECD Countries: A Comparative Analysis,' Population and Development Review, 37(1): 57-87.

Waller, C. (2016). 'These 10 countries have the best parental leave policies in the world,' WEF, accessed 27 March at: https://www.weforum.org/agenda/2016/08/these-10-countries-have-the-best-parentalleave-policies-in-the-world

Warren, T. (2015). 'Work-life balance/imbalance: the dominance of the middle class and the neglect of the working class,' The British Journal of Sociology 66(4): 691-717.

Wilson, E. (1977). Women and the Welfare State. London: Tavistock. 